\title{
Repeated drying and rewetting cycles accelerate bacterial growth recovery after rewetting
}

\author{
Ainara Leizeaga ${ }^{1,2}$ (D) Annelein Meisner ${ }^{1,3} \cdot$ Johannes Rousk ${ }^{1} \cdot$ Erland Bååth $^{1}$
}

Received: 8 September 2021 / Revised: 16 December 2021 / Accepted: 29 December 2021 / Published online: 7 February 2022

(c) The Author(s) 2022

\begin{abstract}
Two patterns of bacterial growth response upon drying and rewetting (DRW) of soils have previously been identified. Bacterial growth can either start increasing immediately after rewetting in a linear fashion ("type 1" response) or start increasing exponentially after a lag period ("type 2" response). The effect of repeated DRW cycles was studied in three soils with different response patterns after a single DRW cycle ("type 1", "type 2" with a short lag period and "type 2" with a long lag period). The soils were exposed to seven DRW cycles, and respiration and bacterial growth were monitored after 1, 2, 3, 5, and 7 cycles. Exposure to repeated DRW shifted the bacterial growth response from a "type 2" to a "type 1" pattern, resulting in an accelerated growth recovery to a pre-disturbance growth rate. Bacterial growth in soils that initially had a "type 1" response also tended to recover faster after each subsequent DRW cycle. The respiration patterns after DRW also indicated the same transition from a "type 2" to a "type 1" pattern. Our results show that exposure to repeated DRW cycles will shape the bacterial response to future DRW cycles, which might be mediated by a shift in species composition, a physiological adjustment, evolutionary changes, or a combination of the three.
\end{abstract}

Keywords Drying-rewetting cycles $\cdot$ Birch effect $\cdot$ Bacterial growth $\cdot$ Respiration $\cdot$ Soil microorganisms $\cdot$ Moisture

\section{Introduction}

Soil moisture is one of the canonical factors regulating soil microbial community composition and activity (Waksman and Gerretsen 1931; Kirchman 2018). Soil moisture not only affects steady-state rates of microbial processes (Manzoni et al. 2012), but fluctuations in moisture will also cause dynamics of microbial activity. Especially drastic changes in soil moisture, like drying and rewetting (DRW) cycles, lead to one of the most dynamic events in soil microbial ecology (Schimel 2018). When a dry soil is rewetted, a large release of $\mathrm{CO}_{2}$ to the atmosphere is observed (Birch 1958;

Ainara Leizeaga

ainara.leizeaga@gmail.com

1 Microbial Ecology, Department of Biology, Lund University, Ecology Building, 22362 Lund, Sweden

2 Department of Earth and Environmental Sciences, The University of Manchester, Michael Smith Building, Oxford Road, Manchester M13 9PT, UK

3 Wageningen University \& Research, Wageningen Research, Droevendaalsesteeg 4, Wageningen, the Netherlands
Kim et al. 2012), which can account for a significant C loss of ecosystems (Schimel et al. 2007; Manzoni et al. 2020).

Most terrestrial ecosystems are exposed to fluctuations in moisture availability. Consequently, soil microbial communities are generally exposed to DRW events. During those events, changes in microbial growth and biomass (Bottner 1985; Kieft et al. 1987; Iovieno and Bååth 2008), as well as in nutrient mineralization and availability, take place (Birch 1958; Fierer and Schimel 2002). DRW cycles can be single events, but it is common that soils are exposed to repeated DRW cycles during the year (Jarvis et al. 2007; Inglima et al. 2009). The effects of DRW cycles on soil C mineralization have frequently been studied in soils from different ecosystems, both in the field (Xu et al. 2004; Tang et al. 2005; Jarvis et al. 2007) and in the laboratory (Orchard and Cook 1983; Mikha et al. 2005; Xiang et al. 2008; Shi and Marschner 2014). In laboratory studies, $C$ mineralization has been found to generally decrease with increasing number of DRW cycles, which has been linked to the depletion of available C (Fierer and Schimel 2002; Mikha et al. 2005). In addition, it has been suggested that soil microbial communities that have been exposed to repeated DRW cycles may become more resistant to an additional DRW cycle 
(Fierer et al. 2003; Evans and Wallenstein 2014a). This is in line with other studies suggesting that exposure to repeated DRW cycles can select for faster growing microorganisms (Fierer and Schimel 2002; Evans and Wallenstein 2012) that can recover to a pre-disturbance state more rapidly (de Nijs et al. 2019). These changes in the community can persist for several weeks after the disturbances (Meisner et al. 2018).

When dry soils are rewetted, bacterial growth and respiration have been shown to be transiently uncoupled (Iovieno and Bååth 2008; Göransson et al. 2013). While respiration rates show high rates immediately after rewetting, bacterial growth rates are very low immediately after the disturbance. Two different bacterial growth response patterns upon DRW have been identified (Meisner et al. 2013). On the one hand, bacterial growth rates start increasing immediately after rewetting in a linear fashion reaching a maximum level, coinciding with an immediate increase in respiration rate after rewetting followed by an exponential decline to moist control levels (henceforth, "type 1" response) (Iovieno and Bååth 2008). On the other hand, bacterial growth rates start to increase exponentially after a clear lag period with no increase in growth (Göransson et al. 2013). In this case, respiration also increases immediately after rewetting but is then sustained over some time, sometimes with a secondary increase in sync with the bacterial growth rate increase. Eventually, respiration decreases to levels matching those before the DRW (henceforth, "type 2" response) (Meisner et al. 2013).

It has been proposed that the bacterial response to DRW will be shaped by the "harshness" of the disturbance as perceived by the bacteria (Meisner et al. 2017). Bacterial communities that experience the drought as a "harsh" treatment will need a longer time to increase their growth rate after rewetting, resulting in a lag period before bacterial growth rates increase ("type 2 " response). In contrast, bacteria that experience the drought event as less "harsh" will increase their growth rates immediately upon rewetting ("type 1" response). Even if harshness is not an absolute quality, it may still be useful as a relative attribute. Thus, longer drying periods and drying soils to very low moisture levels both are considered "harsher" conditions, resulting in "type 2" response (Meisner et al. 2015, 2017). There are indications that bacteria may experience drying-rewetting cycles as less harsh when they are exposed to three DRW cycles in a temperate dry heathland soil, turning a "type 1" response into a "type 2" one (de Nijs et al. 2019). This suggests that with each subsequent DRW cycle, the bacterial community experiences the DRW disturbance as less "harsh" due to previous exposure to a DRW cycle. However, it remains unknown whether this pattern can be generalized to different soils with different response types to single DRW events, as well as how bacteria will respond when exposed to a higher number of DRW cycles.
In the present study, we exposed three different soils to seven DRW cycles. We selected soils to cover a range of bacterial growth patterns upon one DRW cycle. The soils were subjected to seven DRW cycles, and bacterial growth and respiration were followed to characterize the response to rewetting. Based on previous studies, we chose two soils with a "type 2 " response but with different lag periods, as well as one soil that exhibited a "type 1" response with no lag period. We hypothesized that repeated DRW cycles would change the bacterial response after rewetting. This would be seen as a (i) reduction and eventual loss of the lag period for bacterial growth, that is a gradual transition from a "type 2" response to a "type 1" response, a (ii) gradual reduction in the recovery time to pre-DRW growth rates, and (iii) a shift from a sustained respiration response ("type 2") to an immediate maximum followed by continually decreasing respiration rates ("type 1 ").

\section{Materials and methods}

\section{Soils}

Based on previous studies, three soils were selected for the experiment with different response patterns upon rewetting. One was a managed grassland soil from south Sweden, classified as a sandy loamy brown earth soil ( soil S; $\mathrm{pH}_{\text {water }}=6.5$; SOM by loss on ignition $\left.\left(600{ }^{\circ} \mathrm{C}\right)=8.4 \%, \mathrm{WHC}=109.4 \%\right)$. The soil exhibited a "type 1" bacterial growth response after air-drying and rewetting (Fig. 1A). This soil was previously studied by Meisner et al. (2013). The other two soils exhibited a "type 2" bacterial growth response after air-drying and rewetting (Fig. 1A). One of them was collected in Greenland (soil G), and was a soil formed by quaternary deposits on pre-quaternary formations of crystalline, breccia, and plateau basalt lavas $\left(\mathrm{pH}_{\text {water }}=6.8 ; \mathrm{SOM}=2.6 \%\right.$, $\mathrm{WHC}=45.5 \%$ ), which was previously described by Meisner et al. (2017). The other soil was a mixture of soils collected under Alder (Alnus glutinosa) or Beech (Fagus sylvatica) monocultures in Wales (soil W) previously described by Göransson et al. (2013). Both soils were fine loamy brown soils and were mixed since they both exhibited the same bacterial response upon rewetting $\left(\mathrm{pH}_{\text {water }}=5.5 ; \mathrm{SOM}=7.9 \%\right.$, $\mathrm{WHC}=74.3 \%$ ). Soils were sampled in autumn 2014 and the experiments were run within 3 months after sampling. Meanwhile, soils were stored field moist at $5{ }^{\circ} \mathrm{C}$. All soils were then wet-sieved in the laboratory using a 2-mm mesh size before starting the experiment.

\section{Experimental drying and rewetting cycles}

All soils were exposed to 7 repeated DRW cycles (Fig. 1B). For each soil, 6 microcosms $(500 \mathrm{~mL}$ plastic beakers with 


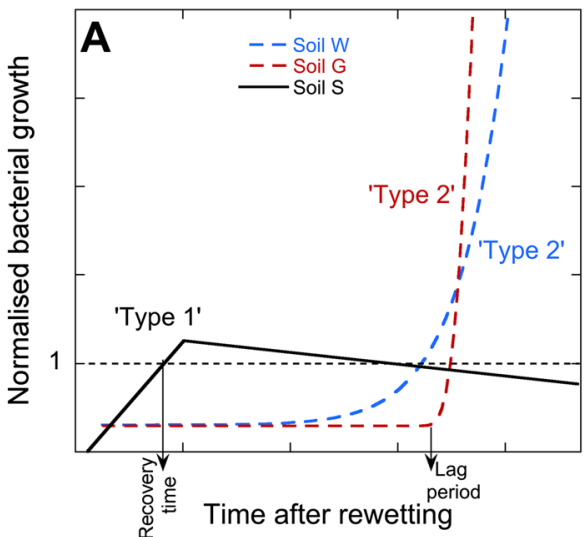

Fig. 1 A Schematic representation of the bacterial growth response to a single 4-day drying and rewetting cycle of the three soils that were used for the experiment. The full black line (soil S) indicates a "type 1" bacterial growth response and the blue (soil W) and red (soil G) dashed lines indicate the "type 2" responses with different lag periods. The dashed horizontal line indicates the bacterial growth level of

lids) were prepared with $60 \mathrm{~g}$ of fresh soil. To dry the soils, microcosms were left without lids under a ventilator at room temperature $\left(\sim 22^{\circ} \mathrm{C}\right)$ for 4 days until they were air-dried (i.e., they reached a constant weight). Then, soils were rewetted to optimum moisture, that is, $50 \%$ of their maximum water holding capacity (WHC). Distilled water was added to the dry soil using a pipette and soil was then mixed with a spatula for approximately $10 \mathrm{~s}$. After rewetting, soils were sampled, measured, and kept in a temperaturecontrolled room at $17^{\circ} \mathrm{C}$.

Bacterial growth and respiration were measured during $48 \mathrm{~h}$ after rewetting. This time frame after rewetting has previously been shown to capture the growth and respiration dynamics after rewetting (Meisner et al. 2013). In order to allow high frequency of measurements during $24 \mathrm{~h}$, soils were rewetted in 2 sets, one rewetted in the evening and the other rewetted in the morning and measured in parallel as previously described (Meisner et al. 2013, 2015, 2017). For bacterial growth, samples were taken approximately every $2 \mathrm{~h}$, whereas for respiration, samples were taken for the following time periods: 0 to $6 \mathrm{~h}, 6$ to $24 \mathrm{~h}$, and 24 to $48 \mathrm{~h}$. Bacterial growth and respiration were measured after cycles $1,2,3,5$, and 7 by destructive sampling of one of the microcosms. The whole experiment was repeated twice with the three different soils.

Controls for each cycle consisted of soils from the previous cycle that was maintained at $50 \%$ WHC. One microcosm was moistened to $50 \% \mathrm{WHC}$ a week before the experiment started and kept moist as a control soil for the first DRW cycle. For the following cycles, soil from the previous cycle was kept moist to use as a control. Thus, the control for the 3rd DRW had undergone 2 cycles and then been kept moist and so on. When the soils exposed to DRW cycles were

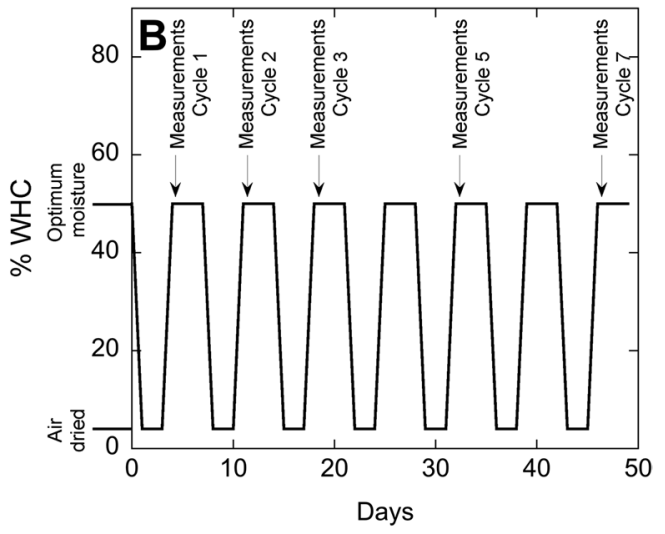

continuously moist soils, which was used to standardize growth data. Since the shown curves are standardized curves, the moist control growth rates equal 1 in the three soils, and thus a single dashed line is shown. B Experimental design indicating changes in the soil moisture during the repeated drying and rewetting cycles. The arrows indicate when the measurements were taken

rewetted and mixed, control soils were also mixed in parallel with cycled soils although no water was added.

\section{Measurements}

\section{Bacterial growth}

Leucine incorporation into bacterial proteins was measured as a proxy for bacterial growth. Measurements of leucine incorporation were done essentially according to the homogenization/centrifugation technique (Bååth 1994), using modifications by Bååth et al. (2001). Shortly, $1 \mathrm{~g}$ of soil was weighed into a $50-\mathrm{mL}$ centrifuge tube and mixed with $20 \mathrm{~mL}$ of distilled $\mathrm{H}_{2} \mathrm{O}$ for 3 min using a multivortex shaker. The soil-water mixture was then centrifuged at low speed (10 min at $1000 \mathrm{~g})$, which resulted in a supernatant with bacterial suspension. A total of $1.5 \mathrm{~mL}$ of the suspension was placed into 2-mL microcentrifugation vials and incubated with radioactively labelled leucine (Leu) for $1 \mathrm{~h}$ at $17{ }^{\circ} \mathrm{C}$. The added mixture consisted of $2 \mu \mathrm{l}$ of $1-\left[4,5-{ }^{3} \mathrm{H}\right]-$ Leucine (5.7 TBq $\mathrm{mmol}^{-1}$, Perkin Elmer, USA) and unlabeled Leu which resulted in a final concentration of $275 \mathrm{nM}$. After incubation, growth was terminated by adding $75 \mu \mathrm{L}$ of $100 \%$ trichloroacetic acid (TCA) resulting in a final concentration of 5\% TCA. Non-incorporated Leu was washed away following the washing steps described by Bååth et al. (2001). Finally, $1 \mathrm{~mL}$ of scintillation cocktail (Ultima Gold; PerkinElmer, USA) was added to the sample and radioactivity was measure using a liquid scintillation counter (PerkinElmer Liquid Scintillation Analyzer, Tri-Carb 2910 TR). Obtained values are presented as pmol Leu incorporated $\mathrm{g}^{-1}$ dry soil $\mathrm{h}^{-1}$. 


\section{Respiration}

Average respiration rates were estimated using gas chromatography for the following time periods: $0-6 \mathrm{~h}, 6-24 \mathrm{~h}$, and $24-48 \mathrm{~h}$. One gram of soil was weighed into $20-\mathrm{mL}$ glass vials. The vials were then purged with pressurized air to have a constant initial background level of $\mathrm{CO}_{2}$ in all samples and sealed. Samples were incubated for the appropriate amount of time and the $\mathrm{CO}_{2}$ production was quantified using a gas chromatograph equipped with a methanizer and an FID detector. Due to technical errors with the gas chromatograph, respiration rates in cycle 5 could not be measured.

\section{Data analysis}

\section{Bacterial growth}

Bacterial growth rates after rewetting were normalized to the control soil growth rates. For the 5th cycle, due to technical issues, we did not have a control soil; instead, the average value of the 3rd and 7th cycle was used to normalize the data.

Since two different patterns after rewetting dry soil were found in the experiment, two types of models were used to model bacterial growth after rewetting (Meisner et al. 2017). When bacterial growth started immediately ("type 1 " response), two linear curves were used to model the response; one for the immediate increase and a second to describe the stable/decreasing phase of the growth. These two curves were separated by the point where bacterial growth reached a maximum that is an inflection point. The inflection point was estimated using a "broken stick model" (Toms and Lesperance 2003) according to the following equation (Leizeaga et al. (2020) using JMP Pro 15 (SAS institute)).

$y=b_{0}+b_{1}(x)+b_{2}(x-C)^{+}+\epsilon$

where $x$ is the time after rewetting, $\mathrm{b}_{0}$ is the intercept, $C$ is the inflection point and finally, $b_{1}$ is the slope before the inflection point, and $b_{2}$ is the difference in slope after the inflection point. The inflection point is $b_{1}+b_{2}$. The variable $(x-C)^{+}$takes the value of 0 for values of $x<C$, and the values $(x-C)^{+}$for values $x>C$.

When bacterial growth after rewetting showed a lag period before it started increasing exponentially ("type 2" response), the response was modelled using a Gompertz equation described by Zwietering et al. (1990):

Bacterialgrowth $=D+A * e^{-e^{B-C x}}$

where $x$ is the time after rewetting, $A$ is the difference between the initial growth after rewetting and the maximum growth, $B$ and $C$ are mathematical parameters modelling the slope and the curvature when bacterial growth is exponential, and finally, $D$ is the growth rate before the beginning of the exponential growth.

After modelling bacterial growth, additional parameters that describe the bacterial growth pattern characteristics were estimated. (i) The lag period indicates time-point at which the bacterial growth rates start increasing exponentially. The lag period is $0 \mathrm{~h}$ in the "type 1 " responses and is calculated using Eq. 3 in the "type 2" responses (Zwietering et al. 1990).

Lag phase $=\frac{B-1}{C}$

(ii) The recovery time was also estimated, which indicates the time that the bacterial growth needs to reach the bacterial growth rates at the moist control soil (50\% WHC).

Spearman's rank correlations were used to test the effect of increasing number of DRW cycles in the lag periods and recovery times. Number of DRW cycles was regarded as an ordinal variable and lag periods and recovery times were continuous.

\section{Respiration}

The "type 1" response is distinguished by high respiration immediately after rewetting, which then declines exponentially. The "type 2" response have a more constant respiration over time or even lower respiration immediately after rewetting than later on. Thus, to be able to compare the respiration response type of all three soils after each DRW cycle, soil respiration was measured 0-6 h, 6-24 h, and $24-48 \mathrm{~h}$ after rewetting. Then a respiration index (RI) of early respiration divided with later respiration was calculated similar to Slessarev et al. (2020). We used the $0-6 \mathrm{~h}$ and $24-48 \mathrm{~h}$ time periods. This ratio was then log-transformed. A "type 1" respiration pattern, where respiration is highest early after rewetting, is characterized by a higher RI; a "type 2" respiration pattern, with similar or even higher respiration in the latter compared to the early phase, will have lower values (Rath et al. 2017; Slessarev et al. 2020).

Spearman's rank correlations were used to test the effect of increasing number of DRW cycles in the RI. Number of DRW cycles was regarded as an ordinal variable and RI was continuous. All the statistical analyses were performed using JMP Pro 15 (SAS institute).

\section{Results}

\section{Bacterial growth}

Bacterial growth after rewetting responded differently to an initial cycle of DRW in the three soils (Fig. 1A), as 
anticipated. Soil S exhibited a "type 1" response where the bacterial growth rate started increasing in a linear fashion immediately after rewetting. In contrast, bacterial growth in the W and G soils exhibited a "type 2" response, where a lag period with almost no growth was followed by exponential growth. The "type 1" soil exhibited a faster recovery to bacterial growth levels in a continuously moist soil compared to the "type 2" soils, with recovery times of $8.5 \mathrm{~h}, 25.0 \mathrm{~h}$, and $32.7 \mathrm{~h}$, in soils S, W, and G, respectively. The "type 2" soils exhibited higher maximum growth rates relative to the control, with maximal levels 5.6 and 13.5-fold higher than in the continuously moist soils for soils $\mathrm{W}$ and $\mathrm{G}$, respectively. Soil G had a longer lag period, $20.6 \mathrm{~h}$, than did soil W, $8.1 \mathrm{~h}$.

The exposure to repeated DRW cycles in a "type 1" response soil (soil $\mathrm{S}$ ) resulted in a consistent "type 1" response pattern after each subsequent DRW cycle (Fig. 2A). In contrast, exposing soils $\mathrm{G}$ and $\mathrm{W}$, with initial "type 2" responses, to repeated DRW cycles resulted in a gradual transition from a "type 2" to a "type 1" response (Figs. 2B, C, D). After the second DRW cycle, these soils still exhibited a "type 2" response, but with a shorter lag period. From the third DRW cycle and on, bacterial growth in these soils always exhibited a "type 1" response after rewetting without a lag period.

The characteristics of the bacterial growth response after rewetting changed with the exposure to additional
DRW cycles, even when the type of response was the same (Fig. 3). The lag period decreased with the number of cycles in the soils that exhibited a "type 2" response (Fig. 3A). The lag period in soil $\mathrm{W}$ decreased from 8.1 to $1.4 \mathrm{~h}$ from the first to the second cycle, whereas in soil $\mathrm{G}$, it decreased from 20.6 to $4.9 \mathrm{~h}$. After three DRW cycles, the lag period had disappeared for both soils, having transitioned into a "type 1" response. Increasing the number of cycles gradually decreased the recovery time (Fig. 3B). A decrease was observed during the first 3 cycles in the soils G and W ("type 2" soils), linked to the reduction and loss of the lag period. In soil W, no further decrease in the recovery time was observed after the third cycle, resulting in a non-significant tendency for a shorter recovery time with more DRW cycles $(\rho=-0.80, p=0.20)$. Soil $\mathrm{G}$ decreased its recovery time with each subsequent DRW cycle (Fig. 3B). There was also a decrease in the recovery time with increasing number of DRW cycles in soil S, which had an initial "type 1" response (Fig. 3B). The recovery time decreased from $8.5 \mathrm{~h}$ after the first DRW cycle to $3.1 \mathrm{~h}$ in the last cycle. Thus, even though there was no change in the response pattern for soil $\mathrm{S}$, bacterial growth needed less time to reach control levels after with subsequent DRW cycles.
Fig. 2 Bacterial growth responses to repeated 4-day drying and rewetting in soils from A Soil S, B Soil W, and C, D Soil G. Panel D is a magnification of $\mathbf{C}$ using only the first $25 \mathrm{~h}$ after rewetting as indicated by dashed square in panel $\mathbf{C}$. The bacterial growth values are normalized to the control $(y=1)$, that is, to the level of bacterial growth of a soil that has undergone one fewer cycle of drying and rewetting. The data points represent the average values of the 2 experiments
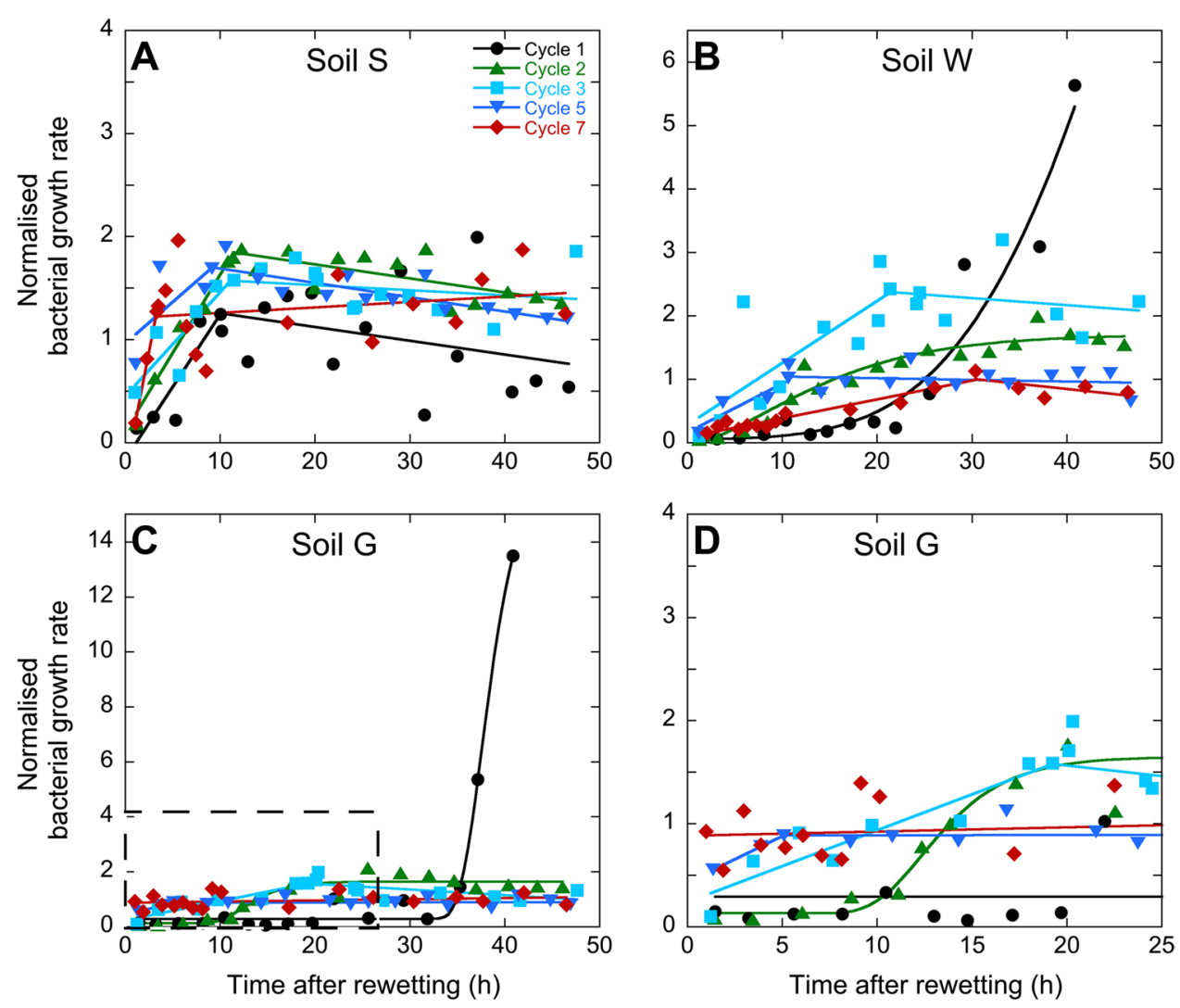

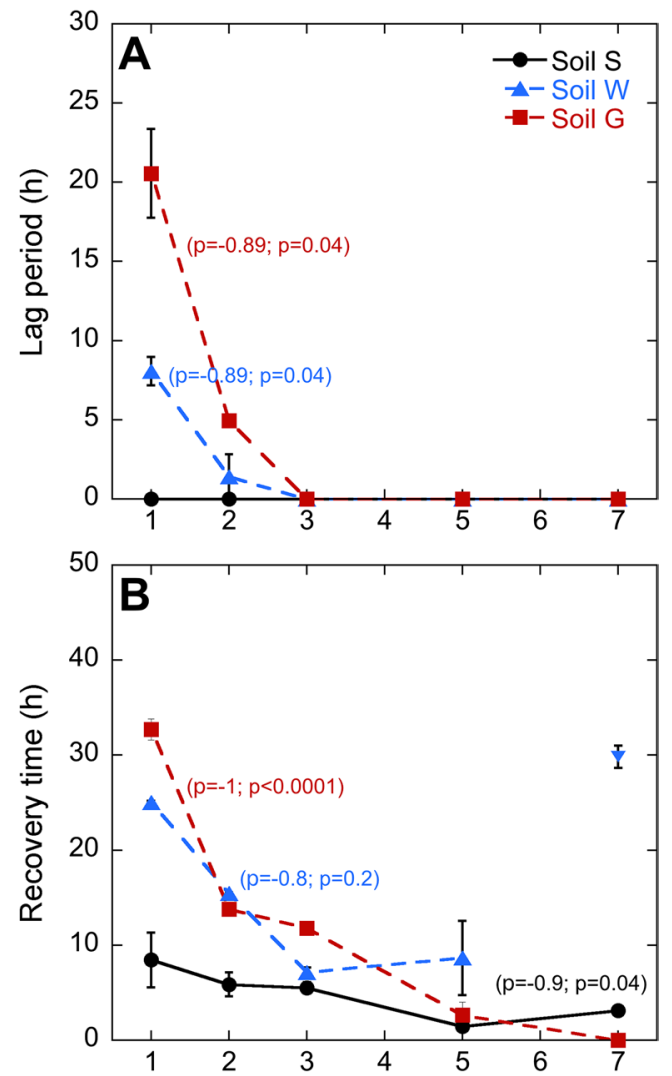

Fig. 3 Bacterial growth characteristics after repeated 4-day drying and rewetting cycles: A lag period and $\mathbf{B}$ recovery time. Black circles and full line indicate soil S, blue triangles and stippled line soil $\mathrm{W}$, and red squares with stippled line soil G. Data points are means $( \pm \mathrm{SE}, n=2)$. We used the average rates of the moist control of cycle 3 and cycle 7 to be able to calculate the recovery time of cycle 5 . The blue inverted triangle without filling indicates an outlier. Brackets next to each curve are the Spearman's correlation coefficient and $p$-value ( $\rho$ and $p$, respectively)

\section{Respiration}

Exposure to repeated DRW cycles generally decreased respiration rates (Fig. 4), but different respiration response patterns upon rewetting were observed. Respiration in soil S peaked immediately upon rewetting and then decreased exponentially after each DRW cycle (a "type 1" respiration pattern), starting from a lower level with each DRW cycle (Fig. 4A). However, soils $\mathrm{W}$ and $\mathrm{G}$ had different respiration responses depending on the number of DRW cycles that they had been exposed to (Fig. 4B-C). After the first cycle, the respiration rate increased immediately upon rewetting for soil $\mathrm{W}$, and was then sustained during the remaining measurement period, suggesting a largely maintained respiration rate during at least $48 \mathrm{~h}$ (a "type 2" respiration pattern). After the second cycle, the respiration rate peaked immediately and then decreased. This decrease was even more pronounced after DRW cycles 3 and 7.
Soil G behaved similarly to soil $\mathrm{W}$, although after the first DRW cycle, the respiration rate even increased during the 24- to 48-h period after rewetting (Fig. 4C). After the second cycle, the respiration rate was sustained during the first $12 \mathrm{~h}$ after rewetting and then decreased. After cycles 3 and 7 , the respiration rate showed an exponential decrease after the immediate peak after rewetting.

A respiration index (RI) was calculated to better capture the two types of respiration responses. The RI differed between the "type 1" and "type 2" soil after the first cycle. Soils W and G had low values of RI, typical for a "type 2" response (Fig. 5), while soil S had high RI values characteristic of a "type 1" pattern. Soil S showed a stable RI during subsequent DRW cycles, indicating that
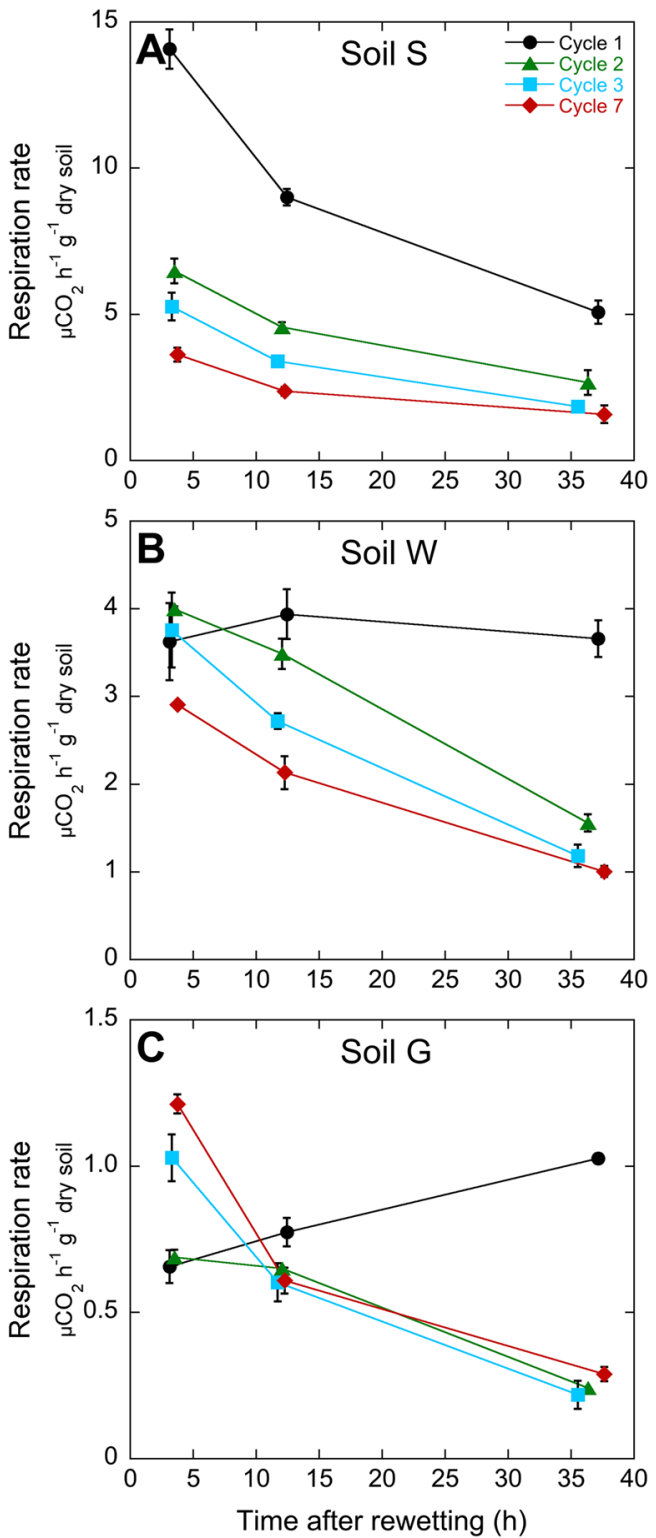

Fig. 4 Respiration rates after repeated 4-day drying and rewetting cycles in $\mathbf{A}$ soil S, B soil W, and $\mathbf{C}$ soil G. Data points are mean respiration rates $( \pm \mathrm{SE}, n=2)$ 
there was no shift in the response pattern. Soils W and $\mathrm{G}$ both had a transition from low values of RI to higher values during the first two DRW cycles. Then, RI was stable over the subsequent cycles for these soils. However, using a Spearman's rank correlation revealed no statistically distinguishable patterns between RI and number of DRW cycles (Fig. 5).

\section{Discussion}

Previous studies have described two types of bacterial response patterns to DRW (Iovieno and Bååth 2008; Göransson et al. 2013; Meisner et al. 2013, 2017; de Nijs et al. 2019). Those studies cover a wide range of responses: from an immediate increase of the growth rate after rewetting ("type 1") to a 20-h lag period before the exponential increase of the growth rate ("type 2"). Here, we use three different soils that cover the whole range: soil $\mathrm{S}$ as a "type 1" soil, soil W as an intermediate "type 2" soil with an 8.1-h lag period, and soil $\mathrm{G}$ as an extreme "type 2" soil with a 20.6-h lag period.

Exposing a "type 2" soil to repeated DRW cycles shifted the response pattern upon rewetting to a "type 1" pattern: the lag period was first shortened and eventually disappeared with increasing number of DRW cycles (Fig. 2B-D). This was in line with our predictions and verifies observations by de Nijs et al. (2019), who showed that exposing one soil to two repeated DRW cycles shifted the response pattern from a "type 2" to a "type 1". However,

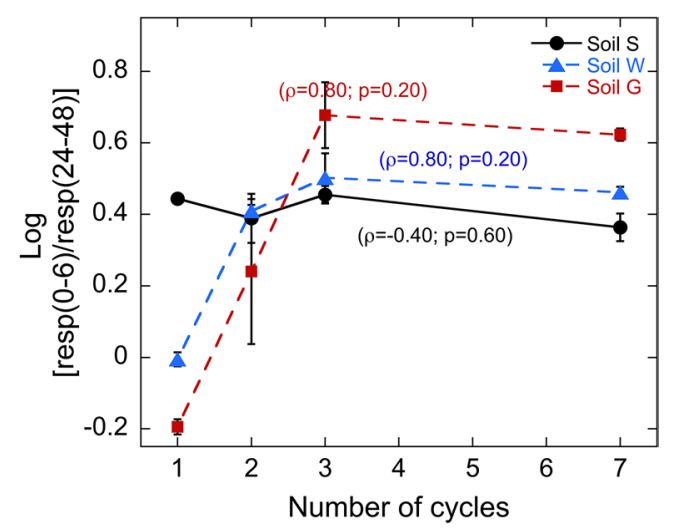

Fig. 5 Respiration index (RI) for "type 1" and "type 2" responses calculated as Log [respiration (0-6 h)/respiration (24-48 h)]. Lower values of the RI indicate a "type 2 " pattern while higher values indicate a "type 1" pattern. Black circles and full line indicate soil S, blue triangles and stippled line soil $\mathrm{W}$, and red squares with stippled line soil G. Data points are mean values $( \pm \mathrm{SE}, n=2)$. Brackets next to each curve are the Spearman correlation coefficient and $p$-value ( $\rho$ and $p$, respectively) our study not only shows the transition in the response pattern, but also shows that this is a gradual transition, as indicated by the recovery times of bacterial growth rates. Thus, "type 1" and "type 2" can be considered extreme levels on a continuum. In addition, in line with our hypothesis, when the "type 1" response soil (soil S) was subjected to repeated DRW cycles, a more rapid recovery time to a pre-disturbance growth level with each subsequent DRW cycle was observed (Fig. 3B), indicating that the bacterial community in this soil also had been affected by repeated disturbances. This gradual decrease in the recovery time with increasing number of DRW cycles was thus a general pattern observed in the three studied soils, which was in line with our expectation (Fig. 3B).

Bacterial growth measured at a high temporal resolution after rewetting has mostly been used to differentiate between the "type 1" and "type 2" response patterns (e.g. Meisner et al. 2013; Rath et al. 2017), since it is a sensitive metric to differentiate between a long lag period or an immediate increase in growth after rewetting. In contrast, soil respiration is often measured at a lower temporal resolution after rewetting a dry soil and therefore does not capture these two types of response patterns (Miller et al. 2005; Xiang et al. 2008; Butterly et al. 2009). However, we have identified a few studies with high temporal resolution where these two response patterns could be distinguished (Göransson et al. 2013; Fraser et al. 2016; Sawada et al. 2016; Slessarev et al. 2020). In a recent study, Slessarev et al. (2020) suggested the use of a respiration index between early and late respiration after rewetting in order to differentiate these patterns. Here, we used a similar respiration index (RI; Fig. 5), showing that we can distinguish between "type 1" and "type 2" responses based on early and late respiration rates. However, more work should be done to determine the threshold in the RI to be able to distinguish the presence of a lag period in the growth responses using respiration assessments. In soils $\mathrm{W}$ and $\mathrm{G}$, there was a shift from a sustained response of respiration after rewetting to a response where the respiration was decreasing rapidly after the immediate increase after rewetting, which resulted in an increase of the RI consistent with a transition from a "type 2" to a "type 1 response (Figs. 4B-C). Similar results can be deduced from respiration data on tropical soils from Thailand and Japan by Sawada et al. (2016), where five DRW cycles resulted in those soils shifting from a "type 2" to a "type 1" response pattern. Fraser et al. (2016) subjected a grassland soil from Wales to four DRW cycles, also resulting in a shift in the response pattern, detectable by respiration data. In the study by Slessarev et al. (2020), the DRW response of several Californian soils was studied. During the preparation of the soils for experiments, they were subjected to one cycle of DRW. Thus, the soils were actually 
exposed to two DRW cycles. The authors found a large proportion of "type 1" responses, which also matches our observations: some soils might actually have had a "type 2 " response during the first DRW cycle, which might have been shifted to a "type 1" response after the second cycle. Taken together, the transition of soils having a "type 2" to a "type 1" response after repeated DRW cycles appears to be a general phenomenon that careful consideration of previously published respiration results can confirm.

The exposure to repeated DRW cycles resulted in bacterial communities that were less constrained by the disturbance, and therefore could recover their growth rates faster, even if the conditions of the DRW treatment did not change. A potential driver for differences in microbial responses to DRW could be the reduction of microbially assimilable C with each added cycle. However, a previous study showed that the storage of moist soil samples (which causes depletion of available C) before DRW would shift response patters from a "type 1" to a "type 2" which is the opposite pattern that we find here. Thus, we interpreted the observed shift as the bacterial community perceiving the same disturbance as less "harsh" after repeated DRW cycles. The response pattern upon rewetting has been suggested to be determined by the "harshness" of the disturbance as perceived by microbes, with a less "harsh" disturbance resulting in a "type 1" response and "harsher" one in a "type 2" response (Meisner et al. 2017). This results in a continuum of responses rather than in a "type 1" and "type 2" dichotomy. Thus, "type 1" and "type 2" responses can be considered extreme levels on this continuum. A partial drying is a less "harsh" disturbance for the microbes, which results in a "type 1" response while air-drying results in a "type 2" response (Meisner et al. 2017). Prolonged drying (a "harsh" treatment) results in a change from a "type 1" to a "type 2 " response with increasing lag times (Meisner et al. 2013, 2015). The combination of drought with inhibitors (e.g. salt, which alters osmotic conditions) results in even "harsher" drying conditions, resulting in a shift from a "type 1" to a "type 2" response (Rath et al. 2017). In all these studies, differences in the extent of the disturbance were the mechanism explaining differences in the "harshness". However, in the present study, we subjected the soils to a standardized disturbance in each cycle: 4 days air-drying followed by rewetting to $50 \%$ WHC. Thus, bacterial communities were affected differently by the same perturbation, suggesting that they perceived the same DRW disturbance as less "harsh". The decrease in the perceived "harshness" with the higher exposure to DRW cycles thus changed the response upon rewetting from a "type 2 " to a "type 1". Therefore, we show that soil bacterial communities not only respond differently to DRW due to variation in the disturbance conditions shown by previous studies (Meisner et al. 2013, 2015, 2017; Rath et al. 2017), but also that a community adjustment to perceive the DRW disturbance as less "harsh" can result in a shift in the response pattern.

There are three main explanations for the shift in bacterial response patterns after repeated DRW cycles. They may be caused by (i) physiological adjustments, (ii) changes in the traits within populations (i.e. evolution), (iii) shifts in the composition of the bacterial community, or a combination of the three. For instance, it is possible for soil microbes to adapt their physiology to resist strong differences in water potentials by changing their intracellular concentrations of osmolytes or due to production of extracellular polymers (Warren 2014; Schimel 2018), giving rise to a physiological change. Likewise, resource competition among microbial populations in culture can give rise to changes in traits linked to substrate use within 10-100 generations (Fiegna et al. 2015) giving rise to evolutionary change. Finally, there is abundant evidence that exposure to a DRW cycle can favour microbial taxa that can better cope with subsequent similar disturbances over other taxa in the studied environment, giving rise to directed and concomitant changes of community composition and functioning (Clark and Hirsch 2008; Evans and Wallenstein 2012, 2014a; Martí et al. 2012; Placella et al. 2012; Barnard et al. 2013, 2015). This will include both bacteria inherently surviving drying better, as well as those being able to respond rapidly after rewetting (Evans and Wallenstein 2014b). It has also been shown that previous exposure to a DRW cycle can affect the function of microbial communities after rewetting, which might be mediated by changes in the microbial community composition (Meisner et al. 2021). Any combination of these three explanations could lead to gradually faster recovery of bacterial growth to subsequent cycles of DRW, and deserve future study.

\section{Conclusions and future research}

Several studies have shown that different soils can have different response patterns after one DRW cycle, with a large variation in lag phase length and recovery times (e.g. Göransson et al. 2013; Meisner et al. 2015; Rath et al. 2017). Our study brings new insights into what is determining the bacterial response to DRW events. We show that the number of previous DRW cycles determines the bacterial response to a subsequent DRW cycle, resulting in a legacy effect. The duration of such a legacy effect and biotic and abiotic factors affecting the extent and time scale for this needs further study. Moreover, it is still unclear whether the different responses are caused by a change in the bacterial community itself or also by changes in the environment. This is a research gap that deserves attention and could be disentangled by cross inoculation experiments. Finally, other 
research questions that need further study are the effects of repeated DRW cycles on the fungal growth responses, which have not been considered here, as well as effects on the microbial community composition.

While predicting the type of bacterial response upon rewetting based on the physical "harshness" of the disturbance is feasible after monitoring environmental factors (e.g. how long the soil was dry, how much the soil was dried etc.), understanding and knowing the history of DRW that a soil has been exposed to in the field is more difficult. In addition, the history of DRW of a soil also includes the extent of drying of each one of the DRW cycles, which will also shape the type of response that bacterial communities will have when a dry soil is rewetted again. Last, we do not know for how long the legacy of earlier DRW events will still be detectable, that is, how rapid and to what extent the transition from a "type 2" to a "type 1" response will reverse under conditions of adequate moisture. Taken together, the history of DRW events will thus obscure attempts to use only abiotic factors such as the length or severity of the drought to elucidate if a soil has a "type 1" or a "type 2" response after DRW.

Supplementary Information The online version contains supplementary material available at https://doi.org/10.1007/s00374-022-01623-2.

Acknowledgements We thank Dr. D. Blok for sampling soil at Disko Island in Greenland and Prof. D.L. Jones for sampling soil in Bangor, UK.

Author contribution AL, AM, JR, and EB designed the experiment. $\mathrm{AL}$ conducted the lab work. AL analyzed the data. AL wrote the manuscript and all authors provided comments on the manuscript draft.

Funding Open access funding provided by Lund University. This work was supported by grants from the Royal Physiographic Society of Lund, the Swedish Research Council Formas [grant no 2018-01315], the Knut and Alice Wallenberg Foundation [grant no KAW 2017.0171], an international career grant from the Swedish Research Council [VR, Grant No. 330-2014-6430] and Marie Sklodowska Curie Actions [Cofund Project INCA600398].

Data availability Data available upon request to the authors.

\section{Declarations}

Conflict of interest The authors declare no competing interests.

Open Access This article is licensed under a Creative Commons Attribution 4.0 International License, which permits use, sharing, adaptation, distribution and reproduction in any medium or format, as long as you give appropriate credit to the original author(s) and the source, provide a link to the Creative Commons licence, and indicate if changes were made. The images or other third party material in this article are included in the article's Creative Commons licence, unless indicated otherwise in a credit line to the material. If material is not included in the article's Creative Commons licence and your intended use is not permitted by statutory regulation or exceeds the permitted use, you will need to obtain permission directly from the copyright holder. To view a copy of this licence, visit http://creativecommons.org/licenses/by/4.0/.

\section{References}

Bååth E (1994) Mesaurement of protein synthesis by soil bacterial asemblages with the leucine incorporation technique. Biol Fertil Soils 17:147-153. https://doi.org/10.1007/BF00337747

Bååth E, Pettersson M, Söderberg KH (2001) Adaptation of a rapid and economical microcentrifugation method to measure thymidine and leucine incorporation by soil bacteria. Soil Biol Biochem 33:1571-1574. https://doi.org/10.1016/S0038-0717(01)00073-6

Barnard RL, Osborne CA, Firestone MK (2013) Responses of soil bacterial and fungal communities to extreme desiccation and rewetting. ISME J 7:2229-2241. https://doi.org/10.1038/ismej. 2013.104

Barnard RL, Osborne CA, Firestone MK (2015) Changing precipitation pattern alters soil microbial community response to wet-up under a Mediterranean-type climate. ISME J 9:946-957. https://doi.org/ 10.1038/ismej.2014.192

Birch HF (1958) The effect of soil drying on humus decomposition and nitrogen availability. Plant Soil 10:9-31

Bottner P (1985) Response of microbial biomass to alternate moist and dry conditions in a soil incubated with carbon-14- and nitrogen15-labeled plant material. Soil Biol Biochem 17:329-337

Butterly CR, Bünemann EK, McNeill AM et al (2009) Carbon pulses but not phosphorus pulses are related to decreases in microbial biomass during repeated drying and rewetting of soils. Soil Biol Biochem 41:1406-1416. https://doi.org/10.1016/j.soilbio.2009. 03.018

Clark IM, Hirsch PR (2008) Survival of bacterial DNA and culturable bacteria in archived soils from the Rothamsted Broadbalk experiment. Soil Biol Biochem 40:1090-1102. https://doi.org/10.1016/j. soilbio.2007.11.021

de Nijs EA, Hicks LC, Leizeaga A, Tietema A, Rousk J (2019) Soil microbial moisture dependences and responses to drying-rewetting: the legacy of 18 years drought. Glob Chang Biol 25:10051015. https://doi.org/10.1111/gcb.14508

Evans SE, Wallenstein MD (2012) Soil microbial community response to drying and rewetting stress: does historical precipitation regime matter? Biogeochemistry 109:101-116. https://doi.org/10.1007/ s10533-011-9638-3

Evans SE, Wallenstein MD (2014) Climate change alters ecological strategies of soil bacteria. Ecol Lett 17:155-164

Evans SE, Wallenstein MD (2014b) Climate change alters ecological strategies of soil bacteria. Ecol Lett 17:155-164. https://doi.org/ 10.1111/ele. 12206

Fiegna F, Scheuerl T, Moreno-Letelier A, Bell T, Battaclough TG (2015) Saturating effects of species diversity on life-history evolution in bacteria. Proc R Soc B Biol Sci 282:20151794. https:// doi.org/10.1098/rspb.2015.1794

Fierer N, Schimel JP (2002) Effects of drying-rewetting frequency on soil carbon and nitrogen transformations. Soil Biol Biochem 34:777-787. https://doi.org/10.1016/S0038-0717(02)00007-X

Fierer N, Schimel JP, Holden PA (2003) Influence of drying-rewetting frequency on soil bacterial community structure. Microb Ecol 45:63-71. https://doi.org/10.1007/s00248-002-1007-2

Fraser FC, Corstanje R, Deeks LK, Harris JA, Pawlett M, Todman LC, Whitmore AP, Ritz K (2016) On the origin of carbon dioxide released from rewetted soils. Soil Biol Biochem 101:1-5. https:// doi.org/10.1016/j.soilbio.2016.06.032 
Göransson H, Godbold DL, Jones DL, Rousk J (2013) Bacterial growth and respiration responses upon rewetting dry forest soils: impact of drought-legacy. Soil Biol Biochem 57:477-486. https://doi.org/ 10.1016/j.soilbio.2012.08.031

Inglima I, Alberti G, Bertolini T, Vaccari FP, Gioli B, Miglietta MF, Cotrufo F, Peressotti A (2009) Precipitation pulses enhance respiration of Mediterranean ecosystems: the balance between organic and inorganic components of increased soil $\mathrm{CO} 2$ efflux. Glob Chang Biol 15:1289-1301. https://doi.org/10.1111/j.1365-2486. 2008.01793.x

Iovieno P, Bååth E (2008) Effect of drying and rewetting on bacterial growth rates in soil. FEMS Microbiol Ecol 65:400-407. https:// doi.org/10.1111/j.1574-6941.2008.00524.x

Jarvis P, Rey A, Petsikos C, Wingate L, Rayment M, Pereira J, David J, Miglietta F, Borghetti M, Manca G, Valenti R (2007) Drying and wetting of Mediterranean soils stimulates decomposition and carbon dioxide emission: the "Birch effect." Tree Physiol 27:929_ 940. https://doi.org/10.1093/treephys/27.7.929

Kieft TL, Soroker E, Firestone MK (1987) Microbial biomass response to a rapid increase in water potential when dry. Soil Biol Biochem 19:119-126

Kim D-G, Vargas R, Bond-Lamberty B, Turetsky MR (2012) Effects of soil rewetting and thawing on soil gas fluxes: a review of current literature and suggestions for future research. Biogeosciences 9:2459-2483. https://doi.org/10.5194/bg-9-2459-2012

Kirchman DL (2018) Processes in Microbial Ecology, 2nd edn. Oxford University Press, New York

Leizeaga A, Hicks LC, Manoharan L, Hawkes CV, Rousk J (2020) Drought legacy affects microbial community trait distributions related to moisture along a savanna-grassland precipitation gradient. J Ecol 109:3195-3210. https://doi.org/10.1111/1365-2745. 13550

Manzoni S, Schimel JP, Porporato A (2012) Responses of soil microbial communities to water stress: results from a meta-analysis. Ecology 93:930-938. https://doi.org/10.2307/23213741

Manzoni S, Chakrawal A, Fischer T, Schimel JP, Porporato A, Vico G (2020) Rainfall intensification increases the contribution of rewetting pulses to soil heterotrophic respiration. Biogeosciences 17:4007-4023. https://doi.org/10.5194/bg-17-4007-2020

Martí E, Càliz J, Montserrat G, Garau MA, Cruañas R, Vila X, Sierra J (2012) Air-drying, cooling and freezing for soil sample storage affects the activity and the microbial communities from two Mediterranean soils. Geomicrobiol J 29:151-160. https://doi.org/ 10.1080/01490451.2010.530341

Meisner A, Bååth E, Rousk J (2013) Microbial growth responses upon rewetting soil dried for four days or one year. Soil Biol Biochem 66:188-192. https://doi.org/10.1016/j.soilbio.2013.07.014

Meisner A, Rousk J, Bååth E (2015) Prolonged drought changes the bacterial growth response to rewetting. Soil Biol Biochem 88:314-322. https://doi.org/10.1016/j.soilbio.2015.06.002

Meisner A, Leizeaga A, Rousk J, Bååth E (2017) Partial drying accelerates bacterial growth recovery to rewetting. Soil Biol Biochem 112:269-276. https://doi.org/10.1016/j.soilbio.2017.05.016

Meisner A, Jacquiod S, Snoek BL, ten Hooven FC, van der Putten WH (2018) Drought legacy effects on the composition of soil fungal and prokaryote communities. Front Microbiol 9:1-12. https://doi. org/10.3389/fmicb.2018.00294

Meisner A, Snoek BL, Nesme J, Dent E, Jacquiod S, Classen AT, Priemé A (2021) Soil microbial legacies differ following drying-rewetting and freezing-thawing cycles. ISME J 15:12071221. https://doi.org/10.1038/s41396-020-00844-3

Mikha MM, Rice CW, Milliken GA (2005) Carbon and nitrogen mineralization as affected by drying and wetting cycles. Soil Biol Biochem 37:339-347. https://doi.org/10.1016/j.soilbio. 2004.08.003
Miller AE, Schimel JP, Meixner T, Sickman JO, Melack JM (2005) Episodic rewetting enhances carbon and nitrogen release from chaparral soils. Soil Biol Biochem 37:2195-2204. https://doi. org/10.1016/j.soilbio.2005.03.021

Orchard VA, Cook FJ (1983) Relationship between soil respiration and soil moisture. Soil Biol Biochem 15:447-453. https://doi.org/10. 1016/0038-0717(83)90010-

Placella SA, Brodie EL, Firestone MK (2012) Rainfall-induced carbon dioxide pulses result from sequential resuscitation of phylogenetically clustered microbial groups. Proc Natl Acad Sci 109:1093110936. https://doi.org/10.1073/pnas.1204306109

Rath KM, Maheshwari A, Rousk J (2017) The impact of salinity on the microbial response to drying and rewetting in soil. Soil Biol Biochem 108:17-26. https://doi.org/10.1016/j.soilbio.2017.01.018

Sawada K, Funakawa S, Kosaki T (2016) Short-term respiration responses to drying-rewetting in soils from different climatic and land use conditions. Appl Soil Ecol 103:13-21. https://doi.org/10. 1016/j.apsoil.2016.02.010

Schimel JP (2018) Life in dry soils: effects of drought on soil microbial communities and processes. Annu Rev Ecol Evol Syst 49:409432. https://doi.org/10.1146/annurev-ecolsys-110617-062614

Schimel J, Balser TC, Wallenstein M (2007) Microbial stress-response physiology and its implications for ecosystem function. Ecology 88:1386-1394. https://doi.org/10.1890/06-0219

Shi A, Marschner P (2014) Drying and rewetting frequency influences cumulative respiration and its distribution over time in two soils with contrasting management. Soil Biol Biochem 72:172-179. https://doi.org/10.1016/j.soilbio.2014.02.001

Slessarev EW, Lin Y, Jiménez BY, Homyak PM, Chadwick OA, D'Antonio CM, Schimel JP (2020) Cellular and extracellular C contributions to respiration after wetting dry soil. Biogeochemistry 147:307-324. https://doi.org/10.1007/s10533-020-00645-y

Tang J, Misson L, Gershenson A, Gershenson A, Cheng W, Goldstein AH (2005) Continuous measurements of soil respiration with and without roots in a ponderosa pine plantation in the Sierra Nevada Mountains. Agric for Meteorol 132:212-227. https://doi.org/10. 1016/j.agrformet.2005.07.011

Toms JD, Lesperance ML (2003) Piecewise regression: a tool for identifying ecological thresholds. Ecology 84:2034-2041. https://doi. org/10.1890/0012

Waksman SA, Gerretsen FC (1931) Influence of temperature and moisture upon the nature and extent of decomposition of plant residues by microorganisms. Ecology 12:33-60. https://doi.org/10.2307/ 1932933

Warren CR (2014) Response of osmolytes in soil to drying and rewetting. Soil Biol Biochem 70:22-32. https://doi.org/10.1016/j.soilb io.2013.12.008

Xiang SR, Doyle A, Holden PA, Schimel JP (2008) Drying and rewetting effects on $\mathrm{C}$ and $\mathrm{N}$ mineralization and microbial activity in surface and subsurface California grassland soils. Soil Biol Biochem 40:2281-2289. https://doi.org/10.1016/j.soilbio.2008. 05.004

Xu L, Baldocchi DD, Tang J (2004) How soil moisture, rain pulses, and growth alter the response of ecosystem respiration to temperature. Global Biogeochem Cycles 18:1-10. https://doi.org/10. 1029/2004GB002281

Zwietering MH, Jongenburger I, Rombouts FM, Vantriet K (1990) Modeling of the bacterial-growth curve. Appl Environ Microbiol 56:1875-1881

Publisher's note Springer Nature remains neutral with regard to jurisdictional claims in published maps and institutional affiliations. 